\title{
Climate Change and Global Warming: Signs, Impact and Solutions
}

\author{
D. S. Matawal and Dafang John Maton
}

\begin{abstract}
There is no gain saying our Planet has changed fundamentally. Our World is undergoing a catastrophic climatic drift and is hotter today than it has been in two thousand years. Global temperatures are believed to be on an ever increasing high, with its attendant consequences and it is feared that the trend will continued if not controlled. Some of the causative agents/ indicators of this menace are human propelled and induced and can be curtailed to the barest minimum. The consequences of not attending to these variables are dire, affecting global temperatures, weather patterns, sea acidity and aquatic life, prevalence of pests and diseases, poor agricultural yield, to mention but a few. This paper is an expose on the imperativeness of, inter-relationship between, and negative impacts of climate change and global warming, on the entire ecosystem. Comparative excerpts are highlighted and solutions proffered.
\end{abstract}

Index Terms - Climate, ecosystem, global warming, weather patterns.

\section{INTRODUCTION}

Climate is defined by the Oxford Learner's Dictionary as the regular pattern of weather condition of a particular place. These weather conditions could be classified into mild, temperate, warm and wet depending on season and/ or location. Conclusive evidences however show a drift from the normal pattern of weather condition to a rather harmful and adverse trend as climate is now known to have a negative effect on the environment and invariably on the Ecosystem, both animate and inanimate [1].

The Planet Earth is known to be surrounded by an atmosphere composed primarily of Nitrogen and Oxygen and is $149,600,000 \mathrm{Km}$ from the Sun. Gases known as GREENHOUSE GASES contribute to the warming of the Earth's atmosphere by reflecting radiation from the Earth's surface (examples are Carbon dioxide, Ozone and Water Vapor). The term which most appropriately describes the aforementioned process is called Greenhouse Effect, which is the warming of the Earth's surface as a result of atmospheric pollution by gases (Encarta Dictionary). It is now feared that the warming effect are being undesirably increased, causing climatic changes and melting Polar Ice caps.

Since the 1980s, research findings have indicated that the Ozone Layer of the Earth's crust, which is the upper layer of the atmosphere where most atmospheric Ozone gas collects

Manuscript received November 20, 2012; revised January 25, 2013.

Dafang John Maton is with Nigerian Building and Road Research Institute (NBRRI), Abuja (e-mail: dafangmaton@yahoo.com) and absorbs harmful Ultraviolet radiation from the Sun, is being depleted by Industrial pollutants such as Chloroflouro carbons (CFCs) which are slowly but surely creating holes on this layer of the atmosphere. This is especially so over the Antarctic with the resultant effect of direct penetration of unalloyed, uncushioned radiation, which poses great danger in ripple-effect sequence on the entire Globe.

It can thus be inferred that Climate change in the context of Global trends affects negatively all forms of life since it leads to land degradation, fresh water shortages, food shortages/ insecurity, Global warming, flooding and shelter/ comfortable accommodation deficits, health care challenges etc [1].

\section{Climate AND Global Change Issues}

The Greenhouse effect is natural and many of these greenhouse gases are actually life-enabling, for without them, heat would escape back into space and the Earth's average temperature would be a lot colder.

However, if the greenhouse effect becomes stronger, and it is, more heat is trapped than needed, and the Earth is becoming less habitable for humans, plants and animals. It can thus be inferred that the ability of greenhouse gases to absorb sunlight is the root cause of global warming.

Carbon dioxide $\left(\mathrm{CO}_{2}\right)$, though not the most potent of greenhouse gases, is the most significant one. As seen in Fig. 1 , it is released into the atmosphere through animal respiration and when wood and fossil fuels burn or decay. When trees are harvested and used in housing, the carbon remains captive in the wood even though it is no longer living but if it burns or decays, the carbon stored in the wood over its life returns to the atmosphere as $\mathrm{CO}_{2}$ [2] .

Human activity has obviously caused an imbalance in the natural cycle of the greenhouse effect and related processes. In Australia, for example, land clearing and burning vegetation release millions of tons of $\mathrm{CO}_{2}$ into the atmosphere every year. Scientific measurement over time reveals a clear correlation between $\mathrm{CO}_{2}$ concentration in the atmosphere and global temperature. Research records also indicate that before the Industrial Revolution, the level of carbon dioxide in the atmosphere was 280 parts per million; today it is $380 \mathrm{ppm}$ [2]. NASA's Earth Observatory is worth quoting, on the effect human activity has on the natural carbon cycle, for example:

"In addition to the natural fluxes of carbon through the Earth system, anthropogenic (human) activities, particularly fossil fuel burning and deforestation, are also releasing carbon dioxide into the atmosphere.

When we mine coal and extract oil from the Earth's crust, 
and then burn these fossil fuels for transportation, heating, cooking, electricity, and manufacturing, we are effectively moving carbon more rapidly into the atmosphere than is being removed naturally through the sedimentation of carbon, ultimately causing atmospheric carbon dioxide concentrations to increase. Also, by clearing forests to support agriculture, we are transferring carbon from living biomass into the atmosphere (dry wood is about 50 percent carbon). The result is that humans are adding everincreasing amounts of extra carbon dioxide into the atmosphere. Because of this, atmospheric carbon dioxide concentrations are higher today than they have been over the last half-million years or longer. Greenhouse gases are essential for our planet; the planet may be able to deal with slightly increased levels of such gases, but too much will affect the health of the whole planet".

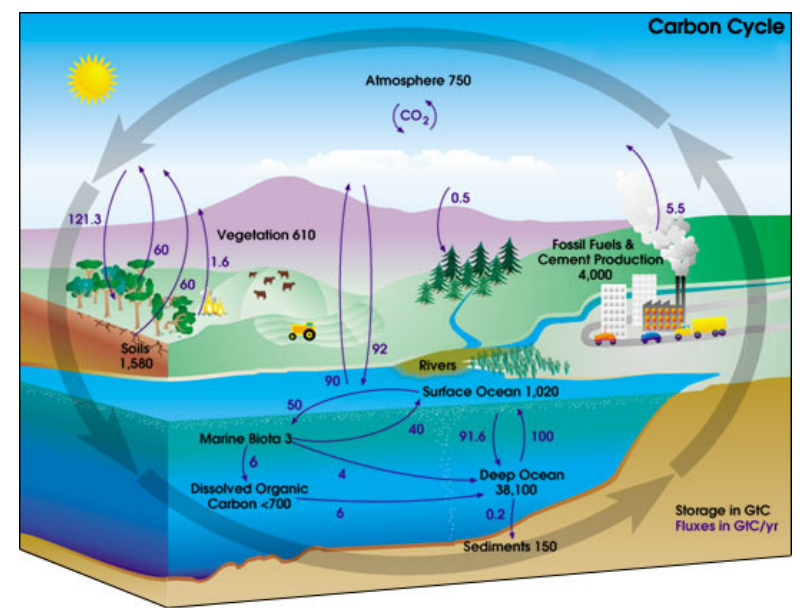

Fig. 1. Carbon cycle. source: NASA.

There are a myriad of consequences that are attendant with the aforementioned situation, some of which are:

\section{A. Air Pollution}

According to the NRDC (Natural Resource Development Council), rising temperatures can make smog pollution worse and increase the number of "bad air days" as in Fig. 2, when it's hard to breathe. This puts many at risk of irritated eyes, noses, and lungs and it is particularly dangerous for people with respiratory diseases like asthma. As the climate changes, unhealthy air pollution worsens [3].

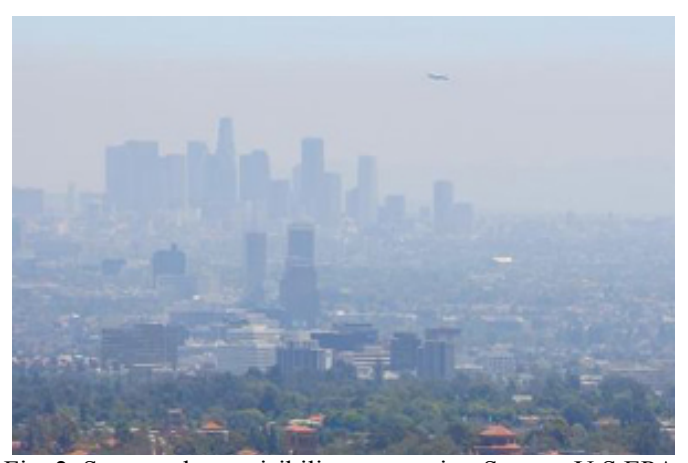

Fig. 2. Smog reduces visibility over a city. Source: U.S EPA

Research findings reveal that people with asthma, allergies, and other respiratory diseases (as in Fig. 3) face the most serious threats, since exposure to increased pollution heightens sensitivity to allergens, impairs lungs, triggers asthma attacks, sends people to the hospital, and even results in death. In 2010, the American Lung Association estimated that about 23 million Americans suffered from asthma [3]. It has also been realized that the prevalence of Asthma in the United States has quadrupled in part due to climate-related factors. For Caribbean Islanders, respiratory irritants come in dust clouds emanating from Africa's expanding deserts, swept across the Atlantic Ocean by trade winds which have been accelerated by warmer ocean temperatures.

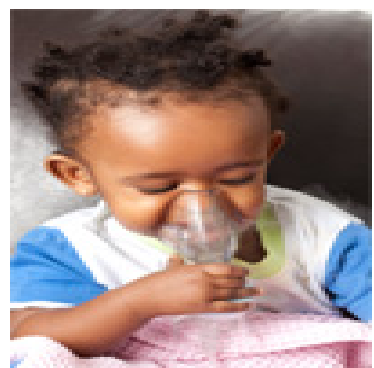

Fig . 3. A respiratory health condition. Source : NRDC

Ozone smog forms from vehicular, factory, and other pollution sources as they react with sunlight and heat. Increasing temperatures speed this process and result in more smog.

\section{B. Diseases}

Warmer temperatures, heavy rainfall and high humidity have reportedly increased the rate of human infections. Many diseases that were reportedly eliminated appear to be resurfacing. For example, for many infectious diseases that were hitherto eliminated from the United States, there's evidence that climate change is a factor that could help them expand their range and make a comeback. In developed countries today it is well known that recurrent influenza epidemics occur in mid-winter.

Dengue Fever, also known as "Break-bone Fever", is characterized by high fever, headaches, bone and joint aches, and a rash [3] and is transmitted by more than 130 Species of Mosquitoes in tropical and subtropical regions [4]. Unlike Malaria however, Dengue Fever is spread by Mosquitoes that thrive in urban areas [5]. Fig. 4, shows a Specie of Mosquitoes and infection by one of the strains will create immunity to only that strain and will unfortunately increase the chances of infection by another strain (Ibid). It has also been established that the number of months with average temperatures above $18 \mathrm{OC}$ and the degree of urbanization correlate with increasing risk of dengue fever [6]. The most deadly strain causes Dengue Hemorrhagic Fever (DHF), and although it is rarely fatal if diagnosed early, it severely damages the circulatory system and internal organs [5]. Recurrent infection can lead to bleeding, seizures, and death [3].

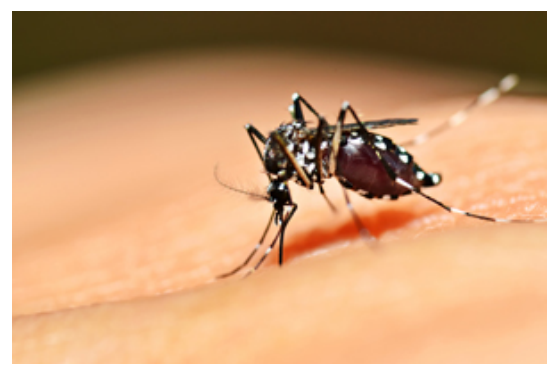

Fig. 4. A disease vector. source: U.S EPA 
The reported case in the U.S is a miniature picture of the global scale: increase in heat, precipitation, and humidity can allow tropical and subtropical insects which act as disease vectors and move from regions where infectious diseases thrive into new places (see Fig. 5). These, coupled with increased international travels to and from various Continents, mean that the Globe is increasingly at risk of an interchange of various diseases, even if through human hosts.

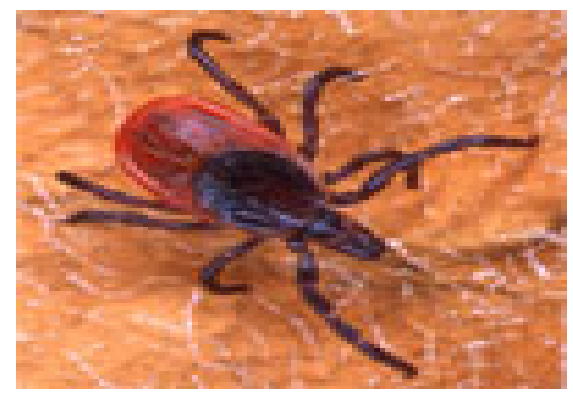

Fig. 5. A disease vector. Source: NRDC

\section{Drought}

Water is life, and climate change is undoubtedly threatening this precious resource. Nearly every U.S. region for example, is facing some increased risk of seasonal drought. With rise in temperature and decreased precipitation, water quality can be jeopardized.

A drought is said to occur when a region stays abnormally dry for a long period of time, such as causes an imbalance in the water cycle. Shrinking amounts of water can concentrate contaminants such as heavy metals, industrial chemicals and pesticides, and sediments and salts. During drought, drinking water supplies are susceptible to harmful algal blooms and other microorganisms. Aquatic life is also endangered as seen in Fig. 6.

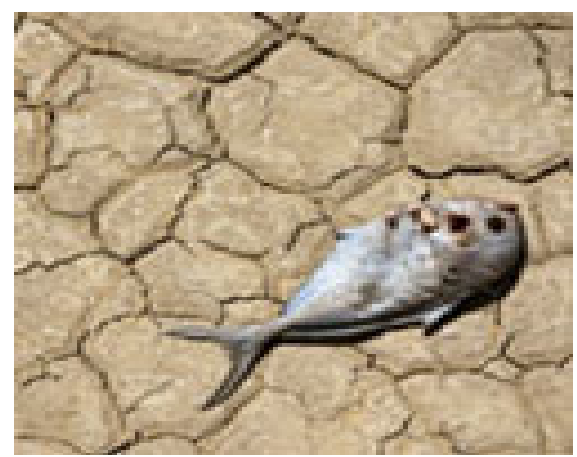

Fig. 6. A typical drought scenario. source: NRDC

According to the Intergovernmental Panel on Climate Change's (IPCC) 2012 report on extreme events, the June 2012 droughts across the Midwest of the U.S, makes the month "one of the 10 worst months" in the past century and farmers in the U.S are slogging through the largest drought in 50 years [7]. Projections indicate that climate change will significantly affect the sustainability of water supplies in the coming decades. As parts of the world get drier, the amount of water available and its quality will likely decrease impacting people's health and food supplies.

The NRDC also says, with some parts of Western U.S. already experiencing water crises because of severe dryspells, and with continued climate change, the entire country will likely face some level of drought. NRDC's Climate Change, Water, and Risk report found that 1,100 counties - one-third of all counties in the lower 48 states - face higher risks of water shortages by mid-century as the result of climate change [8]. More than 400 of these counties will face extremely high risks of water shortages. That again is a mirror to global imperatives in the same vein.

As seen in Fig. 7, such changes in precipitation and water availability could have serious consequences not just for safe drinking water but also for commercial agriculture crops yield less and food security suffers. Drought conditions can also help fuel out-of-control wildfires.

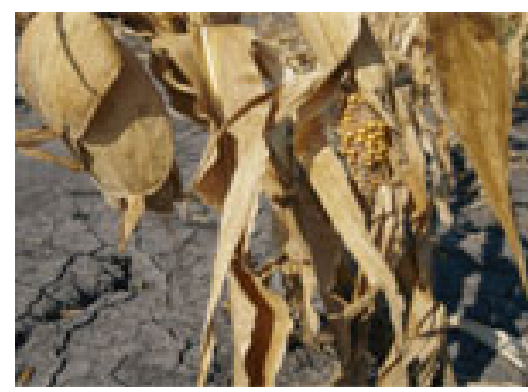

Fig. 7. A typical drought scenario. source: NRDC

\section{Flooding}

Climate change has contributed to a rise in extreme weather events - including floods and higher-intensity hurricanes. Projections by Scientists indicate an increase in the frequency of heavy rainstorms, putting many communities at risk for devastation from floods. This is because warmer air holds more moisture and thus more precipitation [9].

Flooding can cause a range of health impacts and risks, including: death and injury, contaminated drinking water, hazardous material spills, increased populations of diseasecarrying insects and rodents, moldy houses, and community disruption and displacement.

As rains increase, streams, rivers, and lakes tend to overflow, increasing the risk of water-borne pathogens flowing into drinking water sources. Downpours can also damage critical infrastructure like sewer and solid waste systems, triggering sewage overflows that could spread into local waters [8]. Fig. 8 shows the aftermath of Hurricane Katrina on a New Orleans flooded street.

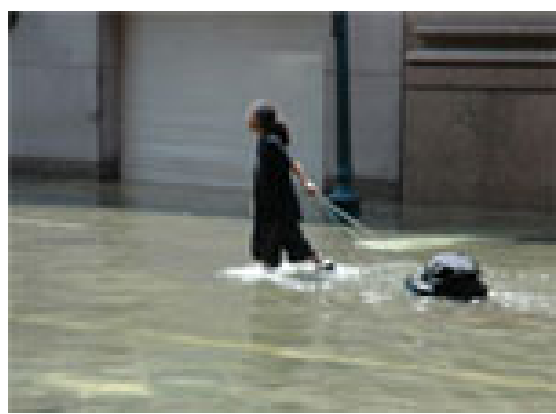

Fig. 8. A typical flood situation. source: NRDC

In Nigeria for instance, flood incidences in 2012 alone have ravaged about seven states of the federation claiming 363 lives and displaced 2.1 million people from their homes, destroying properties and farmlands, whose values are yet to be estimated [10]. 


\section{E. Extreme Weather}

Carbon dioxide $\left(\mathrm{CO}_{2}\right)$ from cars, industries and power plants trap heat near the earth's surface. More heat means more energy and adding so much more energy to the atmosphere creates the potential for more extremes (department of ecology, state of Washington). Thus, droughts, wildfires, heat waves and hurricanes are becoming normal occurrences in America because of climate change [7].

Fig. 9 and Fig. 10 for example, show how global warming brings about more extreme heat waves with urban centers experiencing more of its effect because asphalt, concrete and other structures absorb and reradiate heat, causing temperatures to be as much as $10^{\circ} \mathrm{F}$ higher than nearby rural areas. Washington residents for instance, experienced weather extremes in the fall of 2006. First, record rains churned up rivers and caused landslides and floods around Western Washington. This was followed by record cold with ice and snowfall paralyzing parts of the west side of the state. Closely following was a record gale force wind, 14 deaths, extensive property damage and days of power outages for 1 million homes and businesses in Washington [11].

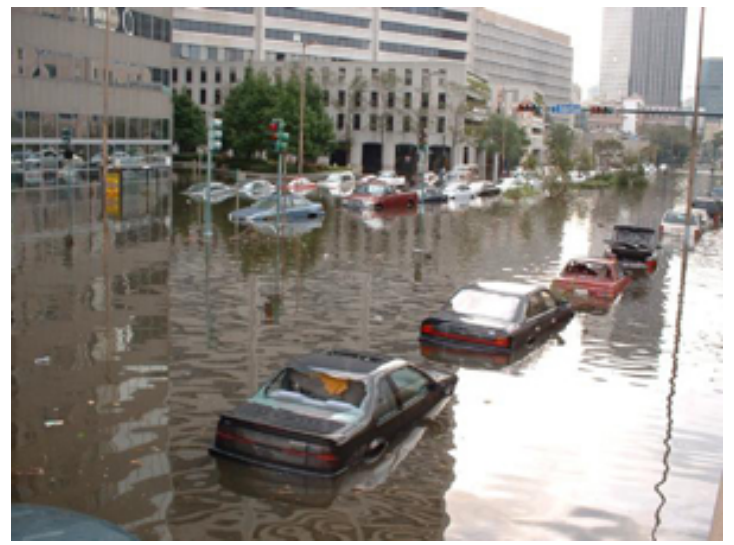

Fig. 9. New or leans after hurricane katrina. source: FEMA (2005)

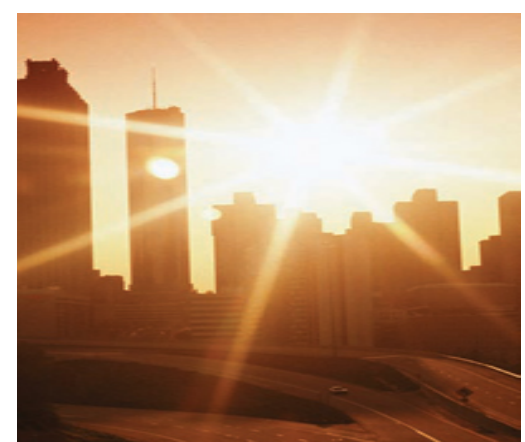

Fig. 10. Extreme sunshine in a city. source: U.S EPA (2010)

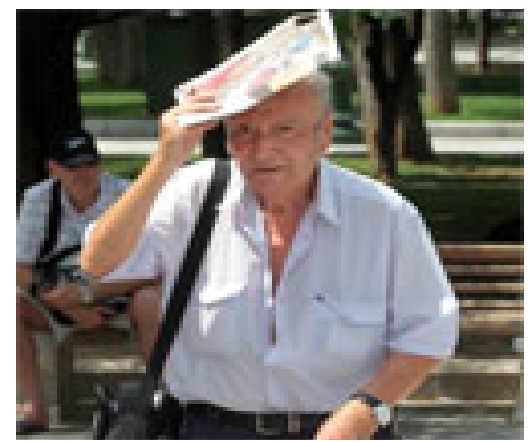

Fig. 11. Extreme heat. source: NRDC

\section{Postulations/ REMEDiATION}

This is a bleak proposition but it is open to remedy. Recent researches seem to indicate that $\mathrm{CO}_{2}$ can be kept out of the atmosphere for many centuries if released into the sea, where phytoplankton when sinking in the seafloor takes the carbon with it [2]. On the other hand, global warming can be addressed through behavioural change, emissions reductions and renewable forms of energy, community education and a new vision. This is because on the most part, $\mathrm{CO}_{2}$ and other greenhouse gases are humanly induced emissions and can be controlled. There are choices regarding sustainability open to the world but steps must be taken now.

The UN Inter-Governmental Panel on Climate Change estimates the world needs to reduce emissions to 40 percent of current levels to stabilize the atmosphere. And since forests are crucial elements in the carbon cycle; they act as air filters taking $\mathrm{CO}_{2}$ from the atmosphere, forestation and/ or landscape architecture should be encouraged and enforced where there are policies backing them.

In photosynthesis, trees use sunlight to make complex carbohydrates like sugar and cellulose from $\mathrm{CO}_{2}$ and water-a process that sequesters $\mathrm{CO}_{2}$ from the atmosphere and releases oxygen. Trees also sequester methane. This adds to the benefit of planting trees adjacent to pastureland (Paul W Newbury). The $\mathrm{CO}_{2}$ trees sequester becomes part of its cells and is released into forest soils. If in a forest, more carbon dioxide is being taken from the atmosphere than is being released through fire or decay, the forest is know as a carbon sink - a measurable amount of $\mathrm{CO}_{2}$ in the trees and soils of the forest. Planting and conserving forests are key factors in carbon emissions trading because the $\mathrm{CO}_{2}$ sequestered can be offset against $\mathrm{CO}_{2}$ released elsewhere.

There is a compelling argument for converting marginal grazing land to native woodlands or forests. The benefits include habitat and biodiversity enhancement, greenhouse gas mitigation and water catchment security. Recent research shows methane uptake is significantly increased and nitrous oxide release is decreased when trees are planted on previously grazed pastureland.

Sustainable development is a term that has found use in various human endeavors particularly as it pertains to Climate Change and Global warming. Some of its principles and benefits are well known and are yet being researched into. Some of them are:

- Sustainable building designs, materials and construction methods.

- Sustainable energy utilization.

- Efficient waste disposal and recycling methods.

- Forestation and/ or landscape architecture.

- Dredging of waterways.

Global Warming and Climate Change are global challenges and the consequences are indeed dire as we have seen and experienced lately, all over the world. It behooves us all therefore, especially governments, to ensure stringent policies and compliance to well known safety principles that will curb these menace, lack of which is tantamount to the extinction of not just some species of animals and plants but also of the human race. 


\section{ACKNOWLEDGMENT}

We wish to acknowledge the following groups and associations for using of their resource in writing this paper:

- NASPA-CCN (National Adaptation Strategy and Plan of Action on Climate Change for Nigeria).

- NRDC (Natural Resources Defense Council).

- NASA (National Aeronautics and Space Administration).

- U.S EPA (United States Environmental Protection Agency)

- FEMA (Federal Emergency Management Agency).

- NEMA (National Emergency Management Agency).

- NBRRI (Nigerian Building and Road Research Institute).

- NWF (National Wildlife Federation).

- IPCC (Intergovernmental Panel on Climate Change).

- Department of Ecology, State of Washington.

\section{REFERENCES}

[1] D. S. Matawal, Contributions of The Nigerian Building and Road Research Institute (NBRRI), to the Memoranda on Climate Change Policy (NCCP) and Adaptation Strategy and Plan of Action on Climate Change for Nigeria (NASPA-CCN).

[2] P. W Newbury, "Global Warming: A natural disaster opens to remedy- A three-part series."

[3] Sneezing and Wheezing: How Global Warming could increase Ragweed Allergies, Air pollution and Asthma. [Online]. Available: http://www.nrdc.org/globalwarming/sneezing/contents.asp

[4] T. W. Chun, "Estimating the economic impacts of climatic change on infectious diseases," A case study on dengue fever in Taiwan, 2008.

[5] N. Brian, "Dengue Fever Outbreak Far Worse Than Swine Flu," Ecoworldly, 2009.

[6] P. Wu et al., "Higher temperatures and urbanization affect the spatial patterns of dengue fever transmission in subtropical Taiwan," Science of the Total Environment, vol. 407, pp. 2224-2233, 2009.
[7] Intergovernmental Panel on Climate Change's (IPCC) [Online]. Available: http://www.ipcc.ch/

[8] Fever Pitch: Mosquito-Borne Dengue Fever Threat Spreading in the Americas. [Online]. Available: http://www.nrdc.org/health/dengue/

[9] National Wildlife Federation. [Online]. Available: http: www.nwf.org /

[10] National Emergency Management Agency (NEMA). [Online]. Available: www.bbc.co.uk/world-africa.

[11] T. R. Karl, J. M. Melillo, and T. C. Peterson, Global climate change impacts in the United States, New York: Cambridge University Press, 2009 .

[12] Impacts of climate change on Washington's economy. [Online]. Available: http: www.ecy.wa.gov/

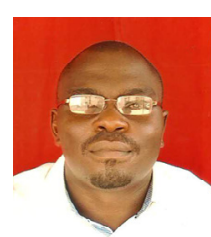

Dafang John Maton was born in Jos, Plateau, Nigeria, on February 10, 1975. He attended Government Science Secondary School, Kuru, near Jos, Nigeria, graduating in November, 1990. He then took to free-lance on-air radio presentations and public speaking, subsequent to which he studied architecture in the University of Jos, Jos-Nigeria and graduated with a B. Sc (Hons) in architecture, 2005. Between December 2006 and March 2012, he worked as architect II and later as architect I, with the Local Government Civil Service Commission. He presently holds an M.Sc degree in architecture (2011) from the University of Jos, Jos-Nigeria and his current employment as Research Officer I, with the Nigerian Building and Road Research Institute, Abuja Nigeria, has exposed him to Workshops, Seminars, Conferences and the ever-versatile field of Research and technical Paper writing with a bias for Sustainable Architectural practices and the built environment.

Mr. Dafang John Maton awaits membership of the Nigerian Institute of Architects' and has recently applied for the membership of the AsiaPacific Chemical, Biological \& Environmental Engineering Society (APCBEES). He has on-going Research works and yet to be published Papers in the areas of Sustainability and the built- environment. 